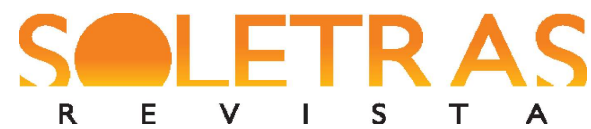
MARIA CLARA COSTA PEREIRA

\title{
A Saudade, periódico de sentimentos identitários portugueses no Oitocentos brasileiro
}

\author{
Carlos Augusto de Melo ${ }^{1}$ \\ Maria Clara Costa Pereira ${ }^{2}$
}

\begin{abstract}
Resumo: Este artigo busca problematizar os usos da palavra saudade com base na análise do periódico A Saudade. Publicado na cidade do Rio de Janeiro entre os anos de 1855 e 1857, este jornal do Grêmio Literário Português foi escrito e lido por portugueses residentes no Brasil que encontraram na imprensa um meio de construção da sua identidade e de um espaço comum em meio aos embates sociais de seu contexto. A literatura de jornal é compreendida enquanto exercício político e artístico que ganha novos tons quando em diálogo com a fabricação sensível de um grupo. A palavra saudade não apenas intitula o periódico como é retomada constantemente na elaboração de um modo de ser próprio daqueles distantes de Portugal. O termo é fundamental na criação do "ser português" enquanto desterritorializado e a desterritorialização não é considerada elemento natural neste processo, antes possui determinados interesses, visando projetos na consolidação de formas de ser e sentir para seu grupo.
\end{abstract}

Palavras-chave: Sensibilidade. Identidade. Saudade. Saudosismo. Literatura.

\section{Introdução}

A alma que revoa incansável e insuficientemente para outros intocáveis tempos, como referência à personagem homérica Tântalo (2001, p. 226), representa o sentimento "saudade" numa das composições literárias que aparecem, em meados do século XIX brasileiro, no jornal, A Saudade .

assim a saudade exprime todos esses queridos affectos da alma que revoa para o passado, e n'elle contempla essas recordações da mocidade, da idade das illusões, das aspirações vagas, do scismar no futuro, dos sonhos dourados de

\footnotetext{
${ }^{1}$ Doutor em Teoria e História Literária no Instituto de Estudos da Linguagem (IEL) da Unicamp. Professor do Núcleo de Literatura do Instituto de Letras e Linguística (ILEEL) e do Programa de Pós-graduação em Estudos Literários (PPLET) na Universidade Federal de Uberlândia (UFU). Brasil. Minas Gerais. E-mail: carlosaug.melo@gmail.com Orcid: http://orcid.org/0000-0001-9305-9519

${ }^{2}$ Doutoranda do curso de Estudos Literários da Universidade Federal de Uberlândia. Brasil. Minas Gerais. E-mail: makla10@hotmail.com Orcid: http://orcid.org/0000-0002-5129-8914

${ }^{3}$ A Saudade - Publicação Litteraria e Instructiva, Jornal do Gremio Litterario Portuguez pode ser consultado virtualmente no Acervo da Hemeroteca Digital Brasileira através do endereço: $<$ http://memoria.bn.br/hdb/periodico.aspx>. Acesso em: 04 abr. 2020.
} 


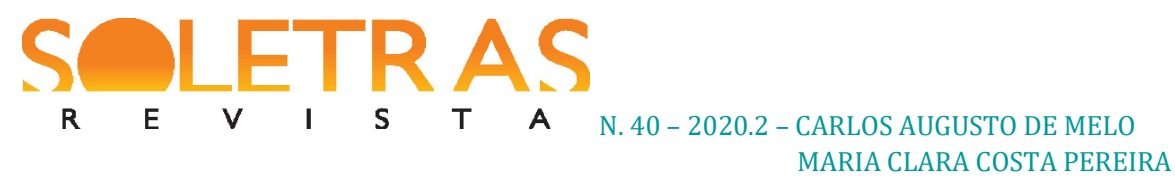

ambições generosas, d'esse ver e crer d'outros tempos, que não poderemos mais tocar, por que em relação ao passado somos como o Tantalo da fábula: desejamos os pomos que vemos, mas não podemos alcançal-os. (A., 1856, p. $1){ }^{4}$

O termo saudade, que dá título ao periódico, coloca em foco uma determinada compreensão do que é o passado e a relação do sujeito saudoso para com ele. Desejar, ver, porém, ser incapaz de alcançar; este paradoxo fundamenta a definição de um modo de ser, instrumento e efeito de significações da saudade. A reflexão sobre as construções de formas de definir e sentir saudade, com base na leitura de escritos literários do jornal A Saudade, é o que fundamenta este artigo.

O que é saudade? Como é sentir saudade? Por que falar de saudade? Quem é o sujeito saudoso? Quais seus desejos e intenções? Respondendo a estas perguntas, ou problematizando a impossibilidade de fazê-las, os textos, em especial os literários, do jornal A Saudade, instituem sentimentos de verdade no que diz respeito às significações da "saudade" no contexto oitocentista. Essas verdades apontam para perspectivas que articulam sentidos em torno do passado, presente e de especulações sobre o futuro, e assim compreensões do que deve ser lembrado e esquecido, os diagnósticos de uma realidade, então, discursiva, e a edificação de projetos que constituem grupos identitários (como, por exemplo, de escritores portugueses desterritorializados). Tal processo cultural é encarado neste artigo enquanto fundamentalmente construtor de saudades, assim como é também construído por elas.

A partir da leitura e análise das aparições de textos literários que tematizam as saudades no periódico, busca-se pensar como a literatura funcionou como um exercício discursivo formativo de uma identidade portuguesa em situação de desterritorialização, na condição do emigrado, ancorado numa sensibilidade saudosa. Esta é compreendida enquanto modo de ser e sentir, calcado em referenciais tradicionais, produto da linguagem literária. Entre sensibilidade e identidade existe uma série de relações frutíferas à crítica e às teorias literárias, cuja reflexão sobre o periódico A Saudade permite potencializar e problematizar.

\footnotetext{
${ }^{4}$ Neste artigo, preferimos manter a ortografia oitocentista dos textos do periódico $A$ Saudade em todas as citações diretas.
} 


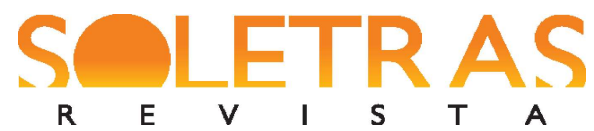

N. 40 - 2020.2 - CARLOS AUGUSTO DE MELO

MARIA CLARA COSTA PEREIRA

Nesse sentido, este estudo convalida a ideia de que os periódicos são um corpus rico para o estudo literário, uma vez que, a partir deles, são criados discursivamente perspectivas, imagens, compreensões e projetos, situados em meio aos embates sociais das práticas históricoliterárias, delimitando os lugares de fala, o pertencimento entre os indivíduos do grupo e suas estratégias para a conquista e manutenção de seu espaço político-cultural na sociedade. Como problematiza Ivana Stolze Lima sobre a imprensa no período regencial: "Lançar um jornal não era simplesmente um ritual de iniciação na arena política - como muitos fizeram -, mas em si mesmo uma forma de compor uma identidade política." (LIMA, 2003, p. 36).

\section{Breve apresentação do periódico $\boldsymbol{A}$ Saudade}

A primeira série do referido periódico foi publicado semanalmente, aos domingos, no Rio de Janeiro entre 05 de agosto de 1855 a 08 de fevereiro de 1857, pelo Grêmio Literário Português, através da Tipografia de Fortunato Antonio de Almeida, totalizando um período de três semestres, separado, respectivamente, em três volumes. Em 15 de abril de 1861 a publicação d'A Saudade é retomada pelo grupo, então, renovado. Desta vez, por meio da Tipografia de Pinheiro \& Comp. . . Esta segunda série persiste até 5 de outubro de 1862, quando o jornal definitivamente deixa de ser publicado.

Não morreu: murchou, e o mesmo sol que a faz pender, reanima-a agora, dálhe todo o viço, todo o frescor.

Como essas rachiticas plantas, que a esterilidade do terreno nunca deixará medrar, mas que transportadas para um solo fecundo, ostentam empouco um brilho esplendido, assim a Saudade, em mãos d'outros cultores, cultores senão mais habeis ao menos mais assiduos, ha de um dia, ousamos espera-lo, acompanhar passo a passo as mais lindas flores do jardim ameno da litteratura. E hade, porque lhe sobram os elementos necessarios para o conseguir.

E hade consegui-lo, porque o sopro ardente das nossas aspirações de mancebos, tem animado mais de uma cousa, e vivificado mais de uma idéa. Aqui a idéa personifica a regeneração de uma classe, e para essa regeneração muitos hão hypothecado já a intelligencia, que symbolisa a idéa, isto é o trabalho do espírito, superior ao trabalho material dos afortunados, por que é a intelligencia do pobre que vira tristemente decorrer os seus melhores dias, entregue ao ostracismo dos preconceitos, que o prendera, ás vezes, ao materialismo, como se prende a parasyta ao trono secular! 
E porque será ele anathematisado, se lhe segreda a consciência que nem o espirito lhe adormecerá traquillo, nem o braço lhe penderá cansado? Romeiro obscuro dos deserto ingratos da litteratura, deixai-o librar as gottas de orvalho suspensas das palmeiras, porque ele cumprirá a sua missão, missão nobre e generosa, que só a comprehende aquelle que tem, mais de uma noute, ao bruxulear da vela humilde, interrogado o livro de tantas gerações como ele condemnadas ao ostracismo em que falamos. (A SAUDADE, 1861, p. 1).

Tal como uma planta que um dia murchou, em 1861, o jornal brota novamente, florescendo sob o mesmo sol, o mesmo ambiente que uma vez a fez perecer. Este ambiente reforça a dificuldade de se manter um periódico e a necessidade sempre renovada de criar um espaço para a consolidação de um grupo e seu discurso. A metáfora utilizada é impactante; remete a uma imagem de esperança e constrói escrita e leitura conjuntamente, um sentimento de recomeço e capacidade de conquistar um reconhecimento da sociedade.

A Saudade (em seus dois momentos de existência) é marcada por diversos tipos de textos, como romances de folhetins, estudos linguísticos, curiosidades, poemas, reflexões existenciais e filosóficas, traduções de textos sobre viagens, notícias e informativos. Sobre as recorrentes temáticas destacam-se o amor à Pátria, a condição do emigrado em terra estrangeira, a tradição literária portuguesa, o ensino de filósofos canônicos, escritores portugueses e brasileiros, os passados gloriosos de Portugal, as virtudes da religião cristã, discussões sobre o casamento, as imoralidades do século XIX dentro outras mais.

O diretor geral da primeira série do periódico foi, até janeiro de 1856, Bernardino Pereira Pinheiro e em seguida F. M. Raposo de Almeida, que abandonou o cargo, deixando-o para seus suplentes, antes do fim do último semestre. Sendo o grupo representado, na sua segunda série, por Reinaldo Carlos Montoro. Esses redatores eram portugueses que residiram no Brasil, condição do principal grupo de leitores do jornal, com quem os textos dialogam, e cuja identificação com a palavra saudade é uma máxima que perpassa suas publicações.

Quando estamos longe da Patria e dessas doces e inebriantes affeições, que nos rodêão na infancia, é um tributo que pagamos registrando em qualquer jornal as saudades pungentes que sentimos pelo torrão natal, os desejos que alimentamos por seus progressos, e a satisfação intima e consoladora que nos move a avivar passadas reminiscencias. (PINTO, 1855, p. 38, grifos do autor). 
Além d'A Saudade, outros periódicos cariocas do período também representavam este grupo identificado pela condição de distância da Pátria portuguesa que busca um meio de veiculação de obras literárias e instrutivas. Entre eles estão: Gazeta Lusitana - Publicação Semanal dedicada à Colônia Portuguesa no Brasil (1883-1888), A Messe - Periódico da Sociedade Retiro Literário Português (1860), O Futuro - Periódico Literário (1862-1863), O Português - Jornal Progressista e Pugnador do Direito dos Portugueses (1861-1865). Essa multiplicidade de periódicos luso-brasileiros evidencia as disputas e conflitos internos ao grupo português residente no Brasil. A Saudade, portanto, materializa uma das vozes que participa de um embate próprio desta identidade emigrada no seio da sociedade brasileira. O jornal cria para seu grupo um espaço e um discurso, assim como também é expressão de uma parcela desse grupo, que disputa com demais, um lugar de fala e representação. Nesse sentido que a história da fundação da associação que encabeça $A$ Saudade é narrada com épica emoção.

Elle [Bernardino Pinheiro] veio acoroçoar o pensamento que todos os sócios nutriam, de se fundar uma folha litteraria, e então foi mudado o nome da sociedade [Luso-Instrutiva], para Gremio Litterario Portuguez. A idéa d'esse honrado socio, que se acha ausente, encheu de jubilo todos os corações d'esses jovens, e causou um enthusiasmo sobremaneira grande. Foram discutidas as bases em que se devia fundar esse Jornal, e apareceu a discordia. A publicação da Saudade, foi apezar d'isso decidica pela maioria. Nada, porém, neste mundo é estavel. Quando se pretendeu pôr em pratica esse pensamento parte dos socios desertaram das bandeiras que haviam jurado, e a sociedade viu-se reduzida a seis socios! A ingratidão de seus companheiros não fez resfriar o animo desses devotados jovens elles poderam conseguir por si, e pelos seus amigos angariar quatrocentas e tantas assignaturas, e a Saudade seguio seu caminho de prosperidade, tendo á frente, como principal redactor o $\mathrm{Sr}$. Bernardino Pinheiro. (OLIVEIRA, 1856, p. 119).

A discórdia narrada no texto demonstra como o projeto de um periódico, assim como o grupo ao qual se faz porta-voz não são homogêneos. Existem ações, perspectivas e sentimentos divergentes que emergem nos textos do jornal. A instabilidade participativa e, consequentemente, econômica d'A Saudade é motivo de orgulho para aqueles que se mantêm, apesar das agruras, firmes ao projeto de veiculação de obras literárias e instrutivas para sua classe, assim como é, também, elemento fundamental numa história de vitória e prosperidade 


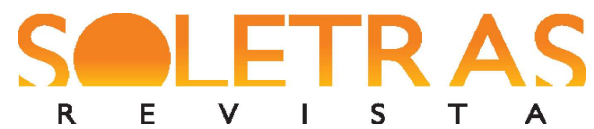

$\mathbf{R}$

A N. $40-2020.2$ - CARLOS AUGUSTO DE MELO

MARIA CLARA COSTA PEREIRA

simbolizada pelo periódico. Os "devotados jovens" aparecem como figuras exemplares e heroicas, de forma a criar, discursivamente, um sentimento de aproximação e pertencimento dos leitores para com os redatores. Todos estes elementos narrativos objetivam, portanto, a construção d'A Saudade enquanto espaço de representação de um coletivo.

\section{Em torno das saudades dos emigrados portugueses}

A literatura é instrumento da vida em sua dinâmica e complexidade, cujo estudo é sempre pouco e insatisfatório, por isso mesmo, extremamente necessário. Reflexões da ordem da sensibilidade e dos produtos artísticos dão visibilidade para uma camada importante da vida em sociedade: as paixões, ou seja, o que move os sujeitos, assim como também são aquilo em que se ancoram para seus exercícios políticos, sociais, culturais. O princípio do qual parte este estudo é fundamentado na compreensão da sensibilidade enquanto produto de um processo artístico e coletivo, de forma que o sentimento saudosista é pensado numa perspectiva interdisciplinar da relação entre história política e teoria literária. O vínculo entre literatura e identidade torna-se mais profundo e complexo quando considerado também o sentimento dentro deste processo.

Saudade!... minha companheira inseparavel, que vens mesmo com teus rigores tornar menos amarga nossa existencia, suavisando nossos pesares quando supportamos a ausencia de objectos que nos são tão charos! Como ainda é suave teu bafejo pensando na quadra não menos risonha, não menos rica de emoções agradaveis, de nossas primeiras affeições amorosas, nessa quadra de existir tão doce, em que por um terno volver de olhos, por um angelico sorriso pairando n'uns lábios de carmim, dariamos sem hesitar vida e thesouros, se thesouros houvessem para fazer permuta com essas joias de tão suido valor! nessa quadra, dizemos, em que o nosso mundo, o nosso existir, a realidade emfim de nossos sonhos fagueiros, andava pendente dos anneis dourados de longa madeixa que a brisa por sobre um collo de virgem, digno do cinzel de Phidias!

Bem feliz o ente que tem um coração capaz de nutrir sentimento tão sublime! Desgraçado, bem desgraçado, aquelle que nunca pôde gozar desse sôpro da Divindade! (CORTIÇO, 1856, p. 83). 
A forma como a palavra saudade é utilizada, significada, poetizada, no periódico $A$ Saudade, diz de uma prática extremamente sensível, a qual busca se instituir como modo de ser que liga um grupo, cuja delimitação ocorre pela condição de afastamento de sujeitos deslocados da pátria portuguesa, local de seu pertencimento identitário. Daí a construção e o fortalecimento do sentimento de pertença ao passado e às memórias pátrias, por meio de um forjado discurso literário, a partir das experiências, muitas vezes voluntárias, de desterritorialização, uma construção, pois, histórica, política e literária de entendimento do que seja o "eu”, o "nós" e o "outro".

Sentir saudades é uma condição comum aos sujeitos, possível de se revelar em plenitude nas experiências poéticas, cuja análise não se justifica num desdobramento sobre si mesmo, mas, principalmente, sobre a forma como a realidade, o mundo, o nós e o outro são significados no processo de formação desse sentimento. Pensar essas formulações é criar uma lente de interpretação das manifestações saudosas que não se perdem em um passado que não toca o presente, ao contrário, não só toca como o constitui. As saudades portuguesas, experimentadas pelos imigrantes residentes no Brasil oitocentista, têm muito a nos ensinar sobre o uso da tradição e do sentimento na construção de um lugar da literatura luso-brasileira em meados do século XIX.

Saudades

Sinto em meu peito affligir-se

Com uma angustia mortal,

Acaso serão saudades

Da minha terra natal?

Do meu berço onde nasci

Do meu lindo Portugal?!

D'esses bosques, lindos bosques,

D'essas floridas campinas,

D'esses prados tão relvosos,

D'essas auras matutinas,

D'essas rosas e açucenas,

Jasmins e tenras boninas?

Ah! que são, e de que mais?

De um pai, que lá deixei,

De meus ternos irmãosinhos

De uma bela a quem amei; 


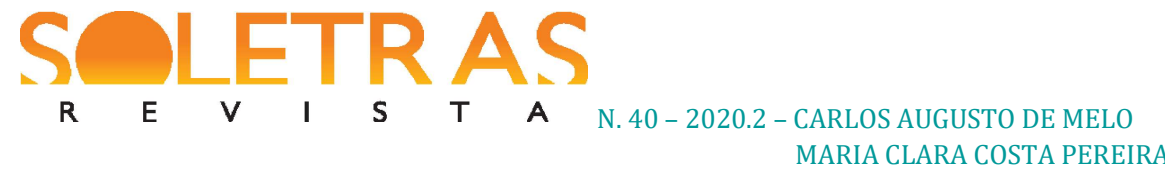

Porém hoje desterrado

Quando vel-os, eu não sei!

Se d'este lugar que habito O triste som de meus ais, Podesse repercutir N'esse lugar em que estais; $\mathrm{Eu}$ já não me entristecia Não lamentaria mais.

Vinde, oh ligeira brisa, Meus gemidos receber, Vinde, vinde, em vossas azas Quando ancioso eu estiver; Levar-me um terno suspiro A' terra do meu nascer.

Setembro de 1855

(LIMA, 1856, p. 6).

O poema de A. J. de Carvalho Lima está presente no número inicial do segundo volume do jornal. Isso é significativo e potencializa o valor e representatividade da temática nele abordada. $\mathrm{O}$ eu desterrado diz de um nós, marcados pela saudade, pela distância da terra natal e uma vivência perpassada pela memória e desejo de retorno. $\mathrm{O}$ espaço, assim como a identidade, é encantado, num processo literário e sensível em que a palavra saudade é elementofundamento.

Neste viés, o estudo das representações das saudades permite pensá-las enquanto elementos-chave na construção de sensibilidades, formas históricas e literárias de sentir que perpassam arranjos íntimos e coletivos em meados do período oitocentista. Os usos da palavra, veiculado no periódico luso-brasileiro, não são encarados enquanto tradução de um superficial "estado de espírito", mas como estratégia na profunda composição narrativa dele, a partir da qual os sujeitos se reconhecem enquanto iguais, tecem laços de pertencimento e se fortificam enquanto grupo que partilha história, sentimento e comportamento. Como escreve Arlette Farge. 
Pode-se também trabalhar sobre essa discreta, e muitas vezes muda, dor das migrações, dos êxodos, dos deslocamentos de pessoas procurando trabalho em todas as regiões, longe de toda sua vida afetiva tradicional, e compreender que através desse sofrimento se tecem novos comportamentos e outras relações de força. (FARGE, 2011, p. 20).

Ao propor o estudo do sofrimento enquanto processo e não consequência ou causa de acontecimentos dados e inquestionáveis, a historiadora reforça a importância das reflexões em torno da subjetividade para as pesquisas que buscam potencializar os aspectos inventivos e fabricados dos objetos e sujeitos, enfocando suas ações, interesses e edificações nas lutas políticas. Daí que os encontros entre literatura, história, subjetividades e sensibilidades amparem questões tão caras às desconstruções de fatos naturalizados, dando a ver os processos, as seleções, os recortes, as apropriações, as ocultações, enfim, como quer Paul Veyne (1995, p. 248) em diálogo com o pensamento foucaultiano, as práticas, a partir das quais são elaborados dizeres sobre o mundo. O periódico A Saudade, enquanto trampolim dessa análise das subjetividades migrantes, impulsiona movimentos reflexivos desta ordem.

Representante d'uma classe olhada com ironia, a Saudade tem apresentado ao publico um desmentido solemne de que as intelligencias são exclusivas das classes distinctas da sociedade. Ella ahi está, corram pagina por pagina, leiam nome por nome, e ver-se-há que nenhuma dessas paginas, nenhum desses nomes sahio das ultimas. O véo da obscuridade que envolve a ambas as cousas, isto é as paginas e os nomes, não é tão impenetravel que não deixe distinguir no fundo a verdade de uma idéa, abraçada por muitos. Essa gloria pertence-nos, o futuro virá para a exaltar, e tenho convicção de que essa classe conquistará o lugar a que tem direito. (PINTO, 1856, p. 193-194).

Esse periódico dá visibilidade a um conflito entre "classes distintas da sociedade" e "classe olhada com ironia", calcando em relação à última um lugar representativo para si, de verdade e de poder. Os usos das saudades aparecem como parte integrante, no jornal A Saudade, dessa orientação e formação de um lugar em meio aos conflitos políticos da sociedade. As (in)definições da saudade se apresentam, nesse sentido, como mecanismos ficcionais que (re)organizam, de forma interessada, o mundo, os espaços, os sujeitos, as condutas, os 
sentimentos. Evocar as "saudades", assim como ocorre com qualquer outro conceito, é uma maneira, ou melhor, uma exigência de entrar na ordem de um discurso (FOUCAULT, 1999), confrontando ou acordando demais imagens saudosas na fabricação de uma nova, uma vez que, segundo Michel de Certeau (1998, p. 226), as “coisas que entram na página são sinais de uma 'passividade' do sujeito em face de uma tradição; aquelas que saem dela são as marcas do seu poder de fabricar objetos.”.

Esta dinâmica literária de enunciar instituindo e/ou destituindo, creditando e/ou condenando, é significativa ao estudo dessa prática discursiva, uma vez que enfoca as múltiplas possibilidades interpretativas para com as produções artísticas. Estas fogem à fixação de uma continuidade explicativa. Daí que os modos de ser saudosos sejam muitos e diferentes, como escreve Durval Muniz de Albuquerque Junior.

A saudade não basta ser sentida para existir, ela deve ser, antes de tudo, conceituada como tal, deve ser nomeada, chamada de saudade e materializada em gestos, ações, reações, performances. Além disso, os sentidos agregados à palavra saudade - seu universo semântico, seu feixe significativo, a constelação de sentidos trazidos por este conceito quando pronunciado variam de época para época. Por isso, sentir saudade nem sempre significa sentir a mesma coisa, e nem sempre o que sentiu como saudade em dado tempo e sociedade continua sendo saudade em tempos e espaços diversos. (ALBUQUERQUE JÚNIOR, 2013, p. 156, grifo do autor).

No movimento contínuo de aprender e ensinar as saudades por meio de sua expressão, principalmente literária, em conjunto com a articulação de demais conceitos, o jornal $A$ Saudade calca um lugar para si. A palavra é seu estandarte, parte integrante e fundamental na fabricação das identidades e, particularmente, das sensibilidades dos portugueses residentes no Brasil ou deles descendentes, dedicados à instrução e à literatura, a partir das quais podem expressar "pensamentos d'amarga saudade que nutris longe da patria” (PINTO, 1856, p. 12). Percebe-se, aqui, essas identidades enquanto constructos, processos narrativos, construídos em meio às lutas políticas, permeados de movimentos e transformações. Essa compreensão de identidade busca investigar os mecanismos discursivos que lhe são intrínsecos e potencializam seu caráter dinâmico. O termo "saudade" tem posição de destaque; ele é enaltecido por sua significação 


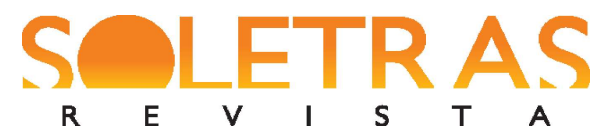

$\begin{array}{llllllll}\mathbf{R} & \mathbf{E} & \mathbf{V} & \mathbf{I} & \mathbf{S} & \mathbf{T} & \mathbf{A} & \text { N. } 40-2020.2 \text {-CARLOS AUGUSTO DE MELO }\end{array}$

MARIA CLARA COSTA PEREIRA

sentimental e universal, assim como é utilizado para delimitar o lugar de um grupo que se define particularmente por seu não-lugar.

E' pois a Saudade um incessante anhelo, um sentir mysterioso de todos os corações, e assim o nosso periodico se denominou - A Saudade, porque sobre tudo será escripto do coração, porque sobre tudo sentimos vivaz desejo de nos tornarmos uteis á nossa patria, e ao paiz onde habitamos. (PRÓLOGO, 1855, p. 1).

Este fragmento faz parte do texto inicial do primeiro número do primeiro volume da primeira série d'A Saudade. A ausência de uma assinatura reforça o sentido de voz coletiva que se direciona a um grupo, discorrendo uma ideia que é ao mesmo tempo instrumento de pertencimento. A diferenciação entre "pátria" e "país onde habitamos" fundamenta o modo de ser e sentir do corpo redator e leitor d'A Saudade, uma sensibilidade, pois, construída e construtora de sentidos e usos da saudade, tal como se dá em relação à referência ao mito de Tântalo, no fragmento que abre este artigo. Por que a dinâmica entre perto e longe, entre desejo (ou necessidade) e incapacidade, entre particular e universal aparece enquanto característica da saudade enunciada no periódico? Em que demais concepções da saudade este discurso se apoia? Ainda que indagações iniciais, estas podem ser pensadas através dos nomes que aparecem n'A Saudade como autoridades e modelos em termos de literatura portuguesa, como Almeida Garrett cujos versos de seu poema Camões, escritos em exílio e definidores da saudade (“delicioso pungir de acerbo espinho que lhe repassava o intimo do peito"), são citados no referido documento introdutório do jornal, Prólogo, para reforçar uma comunhão entre dor e prazer dentro de um sistema significativo da saudade: "Saudade, a mais suave de toda a nossa língua, a que melhor exprime um sentir, ao mesmo tempo doce e amargo, que constante agita o peito do homem.” (PROLOGO, 1855, p. 1).

Essa ambivalência, presente nos enunciados d'A Saudade, integra a criação do mito da saudade, reforçando a relação de sentidos particulares e universais, na elaboração identitária portuguesa, que aparece em obras de literatura, filologia e história, especialmente a partir do final do século XIX e durante o século XX, por escritores portugueses e brasileiros, bem como em jornais e revistas como A Águia (1910-1932) no Porto, representante do movimento 


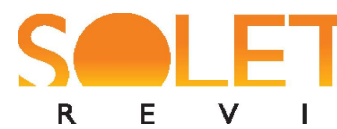

saudosista em Portugal. Os usos da palavra "saudades" atuam, dessa forma, como sentido de um todo sensível. É palavra-chave de uma narrativa, modo de sentir e ser; portanto, justificativa e meio no processo de edificação de um lugar próprio, que compreende a construção cultural da singularidade do grupo português, cuja criação do "mito da saudade" diz de um processo ficcional. Nas palavras de Eduardo Lourenço (1999, p. 14): “Com a saudade, não recuperamos apenas o passado como paraíso; inventamo-lo.”.

Portugal.

Minha terra é a imagem

Do celeste Paraiso;

E' de Deos Omnipotente

O mais brilhante sorriso.

E' um solo abençoado,

A Patria aonde nasci,

As belezas que ella encerra

N'outra parte inda não vi.

Tem cidades mui formosas,

Tem campinas deleitosas,

As frutas são saborosas

Como mais não podem ser;

Produz linho para tela,

Tem o vinho e a canella,

Lá se escuta a Philomela

Pelos bosques a gemer.

Tem um céo onde as estrelas

Fulguram sempre mui belas,

Tem a lua que como ellas

Brilha mais qu'em outra parte;

Tem seus campos plantados

De trigo bem semeiados

Por pastores amestrados

Nesse fértil ramo d'arte.

Tem Coimbra, que tem dado

Ao mundo povo illustrado,

Tem esse Porto abastado

Pelo commercio que faz;

Tem Lisbôa a graciosa,

Cidade rica e formosa,

Cuja barra deleitosa

Ao mundo franqueia em paz 


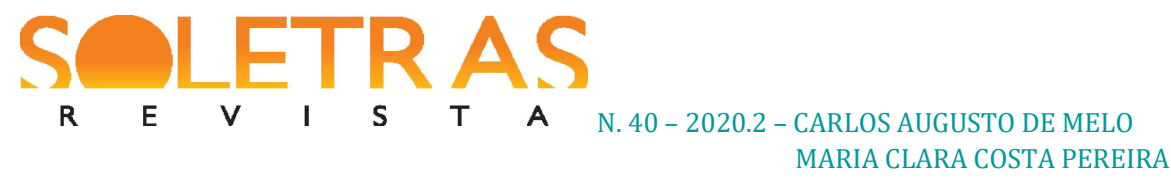

Tem os seus templos sagrados

Que já dos antepassados

A nossos avós legados

Attestam sua grandeza;

Tem um nome engrandecido,

Respeitado e mui temida

Para aquelle que atrevido

A quer forçar á baixeza.

No commercio, nação forte,

Espalha do sul ao norte

Navios de grande porte

Com produtos sem igual.

A minha Patria é sagrada,

Pelos céos abençoada

Em todo mundo é cantada

Minha Patria - Portugal.

Quero muito á minha Patria,

Bella Patria ond'eu nasci,

Por que as bellezas que encerra

N'outra parte inda não vi.

Deos permita que inda veja

Minha Patria um so momento

E tranquilo no seu sólo

Tarde chegue o passamento.

Abril de 1856

(GUIMARÃES, 1856, p. 111-112).

A construção do espaço na literatura é também a construção de uma sensibilidade vinculada ao espaço. Espaço que se figura como identidade, como elo de vínculo de um grupo. Sentir saudades dele é uma forma de ser que delimita seus iguais e seus diferentes. Portugal como Pátria e destino do poeta é uma imagem poderosa e agregadora. Nela está imbricado um sentir saudoso que não apenas identifica, mas aconchega as dores de seus semelhantes.

O diálogo entre as significações dos sentimentos saudosistas em circulação nos textos do periódico $A$ Saudade e a constituição de um grupo português nas terras brasileiras é um lugar paradoxal, pois se fundamenta num pertencimento marcado pelo discurso de não pertencer (à terra em que se habita) e de desejar aquilo que se apresenta muitas vezes como irrealizável (o retorno). A sensibilidade saudosa é, portanto, mecanismo literário de reconciliação deste 
aparente conflito sensível, deste paradoxo. Sua expressão se apresenta como produto dessa tensão, mas é justamente ela que a alivia.

O Grêmio Literário Português, órgão fundador do jornal, se define, através do nome e dos textos, por seu "ser português", que habilita, então, a referência à saudade. Dentre os textos que compõe essa identidade portuguesa que articula narrativas, condutas e sentimentos está o texto Caráter Português em que se lê.

Na luta da nossa independência em 1640, caiu em poder dos espanhóis, já sem forças e mui ferido, um cavaleiro português chamado Roque Antunes; e perguntando-lhe eles.-Q Quem vive? - respondeu com nobre coragem: 'Deus e D. João IV, rei de Portugal' prometeram-lhe a vida se um só vez dissesse viva el-rei D. Filipe. Porém, respondeu com toda a presença de espírito: matai-me, muito embora, que por um tal preço eu não quero a vida. (CARÁTER PORTUGUÊS, 1856, p. 56).

A identificação entre escritores e leitores reforça o aspecto político de delimitação de um território que se materializa no e pelo texto. Este funda um lugar para aqueles marcados pela falta de lugar, ou melhor, caracteriza aqueles sujeitos portugueses em contexto de desterritorialização para com eles delimitarem um grupo e a si atribuírem função e importância representativas em meio aos embates políticos, sociais e culturais portugueses. Como reflete Durval Muniz de Albuquerque Junior (2006, p. 123): "Os românticos portugueses têm saudade de um Portugal que procuram construir como história, fazem história para dela ter saudade.”.

Tal exercício constitutivo pode ser pensado a partir do poema "A pá d'Aljubarrota", publicado no quinto número do primeiro volume da primeira série do jornal. Nele é cantada, de forma épica e orgulhosa, a batalha na cidade de Aljubarrota em 1385. Tal evento é considerado marco histórico e simbólico de consolidação do Estado português e início da Dinastia de Avis (com D. João I), que integra a imagem e o discurso do passado glorioso de Portugal. Figuras lendárias, como a padeira Brites de Almeida (que teria enfrentado e vencido soldados castelhanos com sua pá), são retomadas e lembradas como exemplos de bravura e coragem num processo de criação não apenas da identidade lusa, mas principalmente de sua memória coletiva. 


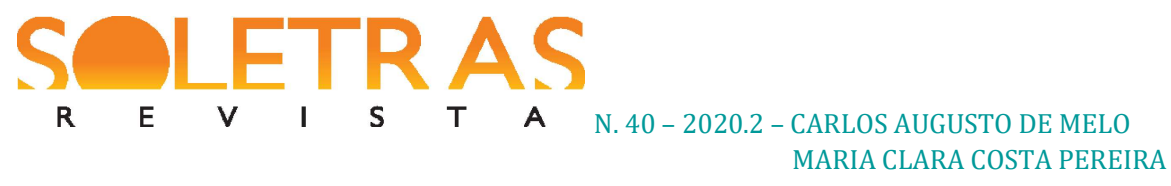

A pá d'Aljubarrota.

Por S. Jorge a vez primeira

O lusitano bradou;

$\mathrm{E}$ a trombeta guerreira

N'Aljubarrota echoou.

D'inimigos trons as balas ${ }^{5}$

Rareando nossas alas,

Davão-lhes maior valor...

Que não farião soldados

Fortes já, ainda animados

Pela crença e pátrio amor? ${ }^{6}$

$\mathrm{O}$ sangue tingia a terra,

O fumo toldava o ar,

E gritava á guerra! á guerra!

A trombeta sem cessar.

De Castella o rei em vista,

Só tinha a facil conquista

Do meu pequeno paiz;

Que são lusos esquecia

Esses valentes, que guia

D. João, Mestre d'Aviz.

Mas assim que os mais ufanos

Começão a recuar,

E', que sete castelhanos

Com a pá pôde prostrar

Brites d'Almeida, a primeira

Que tornou arma guerreira,

Uma pá na sua mão,

E ninguém melhor do qu'ella

Ao orgulho de Castella

Dando tão boa lição...

Lembrou-lhe - já era tarde

E só tinha a escolher,

Ou fugir como caverde,

Ou como bravo morrer.

Fugio... porque já bem via

Que o amor da pátria podia

Mais que todo poder seu.

E, fugindo, lhe lembrava

A vergonha que ganhava,

E a honra que perdeu.

Em signal do vencimento

${ }^{5}$ Peças de artilharia a primeira vez empregadas [em] Portugal nesta batalha. (Nota do periódico)

${ }^{6}$ Os castelhanos eram cismáticos. (Nota do periódico) 
D. João Primeiro quiz

Que s'erguesse um monumento,

Gloria de nosso paiz,

E ainda hoje se nota

$\mathrm{Na}$ villa d'Aljubarrota,

Essa pá que tanta vez,

Depois de centenas d'annos,

Faz corar os castelhanos

E sorrir o portuguez!

J. C. Lousada.

S. Paulo, 1853

(LOUSADA, 1855, p. 39-40).

O jornal A Saudade, assim como demais obras literárias luso-brasileiras do período, aprende e ensina, absorve e fabrica arranjos em que, por exemplo, portugueses são identificados e modelados por conceitos como "bravos", "saudosos", "poetas", "letrados", “instruídos", "religiosos", "dedicados", "trabalhadores" e etc. O discurso age ao passo em que os pés fazem as caminhadas (CERTEAU, 1998, p. 200), ou seja, o grupo se forma, defende seu espaço e lugar na sociedade ao passo em que se elabora literariamente e narra sua história, seu passado comum. Como escreve Glaydes Sabina Ribeiro (2002, p. 29) sobre os jornais: "Atuando no calor da hora, construíam a realidade e eram construídos por ela.”. Trata-se justamente das configurações que o estudo da sensibilidade na literatura se desdobra, pensando, neste caso, as constituições significativas da saudade enquanto elementos participantes de tal processo e não como conceituações neutras e naturais de um grupo ou indivíduo. Essa é uma compreensão em torno do trabalho com textos literários calcada na ideia de que não dizem de um "real" ou de uma "verdade" perdida em um "passado" passível de ser "descoberto" ou "revelado", mas se situam em jogos políticos instituindo para si "verdades", "realidades" e "passados" fluídos, ao passo em que destituem outros discursos numa luta constante. Processo este artístico e sensível, fundamentado no entendimento de que, utilizando as palavras de Roberta Almeida Prado de Figueiredo Ferraz (2007, p. 71), "Se a Saudade, como vimos, deixa de ser apenas um 'sentimento' para se tornar mito da 'alma' da raça, ela só o é, convém frisar, enquanto criação poética.”. 
Buscar saber do sujeito saudoso, seu discurso e elaboração narrativa de sua condição de imigrante, é exercício reflexivo que encara a saudade como estratégia no processo de composição de uma função social, principalmente por meio do literário. Ela identifica e diferencia. O saudoso possui história, corpo, sentimento e lugar.

Depois, sobre as ruinas desse vasto edifício, levantar-se-hia outro que fosse a personalisação da palavra Civilisação, e sobre o tumulo de seus primitivos fundadores escrever-se-hia Litteratura, e os que tivessem sobrevivido o pranto amargo da saudade!... Portugal, poderoso então, acompanhava passo a passo as outras nações. (PINTO, 1855, p. 26).

"Civilização", "Literatura" e "saudade" participam da constituição de um Portugal "poderoso" que "acompanhava passo a passo as outras nações". Seria tal esforço, por parte de um grupo português, saudosismo de outros tempos? Confronto em relação a demais construções em torno da história de Portugal? Reação contra movimentos antilusitanos, lusofóbicos? Delimitação de uma classe? Estas são questões que indicam interpretações possíveis para com este discurso que funciona construindo e reforçando laços de pertencimento, em que sentimentos, lugares e identidades são narrados e significados em prol de determinados projetos políticos. Maria Odila Leite da Silva Dias aponta para a distinção e, inclusive, aversão a portugueses no século XIX no Brasil enquanto parte dos conflitos próprios desta sociedade, que permitem pensar seus mecanismos de funcionamento. Segundo a autora:

Não se tratava de um mero preconceito chauvinista relacionado com a separação da metrópole; era um conflito interno inerente à sociedade colonial e que mesmo o Império não superaria. A lusofobia transparece continuamente nos desabafos da imprensa através de todo o século XIX, nas reivindicações dos 'praieiros' da corte e de Pernambuco (1848) pela nacionalização do comércio a varejo, repetindo-se em muitos outros episódios esparsos de violência, como o que se dá em Macapá e em Goiânia, em 1873, e pela Primeira República adentro. (DIAS, 2005, p. 31). 


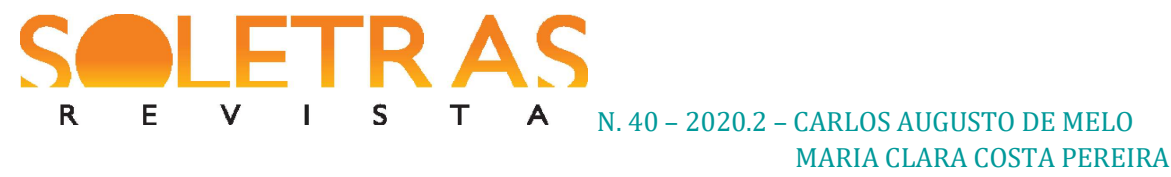

A imprensa oitocentista é um documento repleto de criações literárias e identitárias que participam destes embates políticos. Os poemas, contos e textos dissertativos d'A Saudade, por exemplo, falam do português e de Portugal num cenário de conflitos da sociedade brasileira como forma de situar estes sujeitos e criar um meio de materialização dos seus discursos frente a um emaranhado de disputas pelo poder que ameaçam o grupo. Qual seria o porquê de se falar com orgulho do passado de sua pátria distante? De reverenciar autores portugueses canônicos? De instruir o coletivo dentro de memória histórica sempre ficcionalizada e renovada no presente? Este projeto que se figuras nas páginas do periódico não está desvinculado de sua realidade social. A saudade, a dor, a tristeza, a lembrança são elos, ou melhor, vozes que definem o "nós" emigrado. Bradando esta voz estes sujeitos resistem e lutam.

O emigrado

Minha irmã, como é triste esta vida,

Tão distante da terra natal;

Não te lembras dos dias passados,

Lá nas várzeas do bom Portugal.

Não te lembras da nossa montanha, Do balido da ovelha gentil, Quando à sombra do velho carvalho, As manhãs se passavam d'Abril?

Não te lembras do lago sereno, Onde um cisne se vinha banhar, Com que os ledos meninos da aldeia Vinham todos na margem brincar?

Minha irmã, não te lembras d'amiga, Companheira de nós, infantil, De Lucinda de louros cabelos, Com seus olhos celestes d'anil?

De Lucinda, a formosa, a ingênua, De Lucinda de meu coração, Que o bom padre da nossa igrejinha Queria dar-me em sagrada união.

Minha irmã, minha irmã, quem me dera A montanha e o carvalho real, E Lucinda por minha esposada, Lá nas terras do meu Portugal. 
Rio, 20 de agosto de 1855.

(B. P., 1855, p. 120).

Portugal aparece, não apenas neste poema como em outros mais do jornal, como um espaço idílico, acessível apenas pela memória, lugar da infância e de um tempo que não volta mais. Não caberia, na construção deste discurso, lembrar as agruras que levaram o indivíduo a emigrar. Os aspectos ruins e infelizes do passado não entram nesta elaboração, são "esquecidos", ao passo que os momentos e objetos alvos da saudade são recorrentemente retomados no processo de composição desta identidade, marcada por uma determinada relação sensível com o hoje e com o que se foi. O presente, caracterizado pela triste vida distante da terra natal, se choca com o universo encantado, mágico e feliz versado com profundo sentimento.

As revelações das lembranças saudosistas do emigrado se tornam condição para o leitor experimentar o lugar de fundação do sentimento identitário português enquanto constituição ficcional dos sujeitos (escritores e leitores). Se construir literariamente é, neste caso, demarcação social e cultural de um sujeito estrangeiro inserido num espaço longínquo num contexto histórico de conflitos políticos em que, nas primeiras décadas do século XIX, construções como "ser português" e "ser brasileiro" estão sendo delimitadas ou modificadas, de acordo com interesses hegemônicos, variando de documento para documento, período para período, de forma que os confrontos entre ambas as identidades (portuguesa e brasileira) ora aparecem reforçados, ora amenizados (RIBEIRO, 1997, p. 64).

\section{Considerações Finais}

Neste artigo, a palavra saudade é compreendida enquanto conceito pelo seu aspecto discursivo, literário e histórico. Daí que "saudade" não seja consequência de determinados acontecimentos, mas o próprio acontecimento, conforme ideias de Jacques Rancière (1995, p. 239) sobre o produto artístico, incluindo o linguístico, enquanto o acontecimento ele mesmo 
em contraposição à ideia de representação. Afinal, se em meados do século XIX, no Rio de Janeiro, há a aparição desse termo em estreita relação com a constituição sensível de um coletivo português e suas atividades, tal enunciação dá a conhecer uma disputa e vontade de diferenciação que se expressa na língua, na história e no sentimento, de forma que o uso da saudade atua como elo destas instâncias.

Assim como os escritos d'A Saudade, este artigo também entra no discurso saudoso, buscando instituir um novo lugar para esse periódico e as ideias que o sustentam. Não há um intuito de tomar os pomos de Tântalo, lembrando a referência do trecho que abre este artigo, como quem desvela um passado estático ou uma verdade oculta. Talvez a impossibilidade metafórica do mito de se saciar seja fortuita para este estudo no sentido de dizer, antes, de um interminável fazer reflexivo, não porque os pomos sejam demasiado inalcançáveis, mas porque o prazer está na busca e exige sempre renovações, uma vez que os acontecimentos não estão dados, mas são recorrentemente reelaborados e subjetivados. Como escreve Umberto Eco: "Essa é a função consoladora da narrativa - a razão pela qual as pessoas contam histórias e têm contado histórias desde o início dos tempos. E sempre foi a função suprema do mito: encontrar uma forma no tumulto da experiência humana.” (ECO, 1994, p. 93). É, pois, retramando os acontecimentos que esta pesquisa sobre os usos da saudade defende o seu porquê e trilha seu caminho, acadêmico e existencial, não rumo aos pomos, mas em meio a eles. Como escreve Paul Veyne: "Nesse mundo, não se joga xadrez com figuras eternas, o rei, o louco: as figuras são o que as configurações sucessivas no tabuleiro fazem delas.” (VEYNE, 1995, p. 275).

\section{Referências}

A Saudade - Publicação Literária e Instrutiva, Jornal do Grêmio Literário Português. Rio de Janeiro, série I, v. I, II e III, 1855-1857. Disponível: $<$ http://memoria.bn.br/hdb/periodico.aspx>. Acesso em: mai. 2020.

A Saudade - Periódico Literário. Rio de Janeiro, série II, v. I e II, 1861-1862. Disponível: $<$ http://memoria.bn.br/hdb/periodico.aspx>. Acesso em: mai. 2020.

A SAUDADE. A Saudade. Rio de Janeiro, série II, v. I, n. 1, p. 1-2, segunda-feira, 15 abr. 1861. 
ALBUQUERQUE JÚNIOR, Durval Muniz de. "As sombras do tempo: a saudade como maneira de viver e pensar o tempo e a história". In: História e Sensibilidade. Marina Haizenreder Ertzogue e Temis Gomes Parente (org.). Brasília: Paralelo 15, 2006, p. 117-139.

ALBUQUERQUE JÚNIOR, Durval Muniz de. História: a arte de inventar o passado. Ensaios de teoria da história, Bauru, SP: Edusc, 2007.

ALBUQUERQUE JÚNIOR, Durval Muniz de. "Pedagogias da saudade: a formação histórica de consciências e sensibilidades saudosistas. A vida e o trabalho do poeta e professor português António Corrêa d"Oliveira". Revista História Hoje, vol. 2, n. ${ }^{\circ}$ 4, 2013, p. 149-174.

CARÁTER PORTUGUÊS. A Saudade. Rio de Janeiro, série I, v. II, n. 7, p. 56, domingo, 23 mar. 1856.

CAPELATO, Maria Helena Rolim. A imprensa na História do Brasil. São Paulo: Contexto/EDUSP, 1988.

CERTEAU, Michel. A invenção do cotidiano: Artes de fazer. $3^{\text {a }}$ Edição. Petrópolis: Editora Vozes, 1998.

CORTIÇO, J. A. Santos. A Saudade. A Saudade. Rio de Janeiro, série I, v. II, n. 11, p. 83, domingo, 20 abr. 1856.

DIAS, Maria Odila Leite da Silva. A interiorização da metrópole e outros estudos. São Paulo: Alameda, 2005.

ECO, Umberto. Seis passeios pelos bosques da ficção. Tradução Hildegard Feist. São Paulo: Companhia das Letras, 1994.

FARGE, Arlette. Lugares para a história. Tradução Fernando Scheibe. Belo Horizonte: Autêntica Editora, 2011. (Coleção História e Historiografia, 3/coordenação Eliana de Freitas Dutra).

FERRAZ, Roberta Almeida Prado de Figueiredo. "O mito da saudade: Ambivalência criativa em Teixeira de Pascoaes”. SOLETRAS, Ano VII, n. ${ }^{o}$ 13. São Gonçalo: UERJ, jan./jun. 2007.

FOUCAULT, Michel. Microfisica do poder. Rio de Janeiro: Edições Graal, 1979.

FOUCAULT, Michel. A ordem do discurso. Tradução de Laura Fraga de Almeida Sampaio. São Paulo: Edições Loyola, $5^{\text {a }}$ edição, 1999.

GUIMARAES, J. Augusto da Silva. Portugal. A Saudade, série I, v. II, n. 14, p. 111-112, domingo, 11 maio 1856.

HOMERO. Odisseia. Tradução Carlos Alberto Nunes. Rio de Janeiro: Ediouro, 2001. 

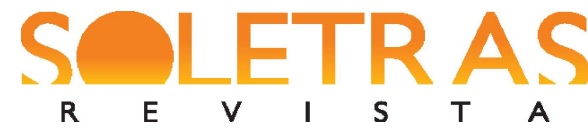

N. 40 - 2020.2 - CARLOS AUGUSTO DE MELO

MARIA CLARA COSTA PEREIRA

LIMA, A. J. de Carvalho. Saudades. A Saudade, série I, v. II, n. 1, p. 6, domingo, 10 fev. 1856.

LIMA, Ivana Stolze. Cores, marcas e falas: sentidos da mestiçagem no império do Brasil. Rio de Janeiro: Arquivo Nacional, 2003.

LOURENÇO, Eduardo. Mitologia da saudade: seguido de Portugal como destino. São Paulo: Companhia das Letras, 1999.

LOUSADA, J. C. A pá d'Aljubarrota. A Saudade, série I, v. I, n. 5, p. 39-40, domingo, 2 set. 1855.

P. B. O emigrado. A Saudade. Rio de Janeiro, série I, v. I, n. 15, p. 120, domingo, 20 ago. 1855.

PINTO, Antônio Xavier Rodrigues. Literatura: páginas íntimas. A Saudade. Rio de Janeiro, série I, v. II, n. 25, p. 193-194, domingo, 27 jul. 1856.

PINTO, Antônio Xavier Rodrigues. Literatura e Civilização. A Saudade. Rio de Janeiro, v. I, n. 4, p. 26, 26 ag. 1855.

PINTO, Antônio Xavier Rodrigues. Damaso Papa. A Saudade. Rio de Janeiro, série I, v. I, n. 5, p. 37-38, 2 set. 1855.

PINTO, J. R. Fragmento de uma carta. A Saudade, série I, v. II, n. 2, p. 11-12, domingo, 17 fev. 1856.

PRÓLOGO. A Saudade. Rio de Janeiro, série I, v. I, n. 1, p. 1-2, domingo, 5 ag. 1855.

RANCIÈRE, Jacques. Políticas da escrita. Tradução de Raquel Ramalhete. Rio de Janeiro: Ed. 34, 1995. (Coleção TRANS).

RIBEIRO, Glaydes Sabina. A liberdade em construção: identidade nacional e conflitos antilusitanos no Primeiro Reinado. Tese (doutorado) - Universidade Estadual de Campinas, Instituto de Filosofia e Ciências Humanas, Campinas, SP, 1997.

R. d'A. A Saudade: ao voar da pena. A Saudade. Rio de Janeiro, série I, v. II, n. 1, p. 1-2, domingo, 10 fev. 1856.

VEYNE, Paul. Como se escreve a História. Brasília: UnB, 1995.

\section{A Saudade, periodic of Portuguese identity feelings in the Brazilian nineteenth century}




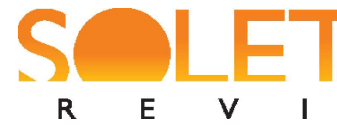

\begin{abstract}
This article seeks to problematize the uses of the word saudade based on the analysis of the journal $A$ Saudade. Published in the city of Rio de Janeiro between the years 1855 and 1857, this newspaper of Grêmio Literário was written and read by Portuguese residents in Brazil who found in the press a way of building their identity and a common space amid social struggles context. Newspaper literature is understood as a political and artistic exercise that gains new tones when in dialogue with the sensitive fabrication of a group. The word saudade not only entitles the periodical but is constantly taken up in the elaboration of a way of being proper to those distant from Portugal. The term is fundamental in the creation of "being Portuguese" while desterritorialized and desterritorialization is not considered a natural element in this process, but rather has certain interests, aiming at projects in the consolidation of ways of being and feeling for the group.
\end{abstract}

Keywords: Press. Sensitivity. Identity. Literature. Saudade.

Recebido em: 18 de maio de 2020.

Aceito em: 15 de julho de 2020. 